Check for updates

Cite this: RSC Adv., 2019, 9, 20137

\title{
Characterization of glycan isomers using magnetic carbon nanoparticles as a MALDI co-matrix $\dagger$
}

\author{
Alireza Banazadeh, ${ }^{a}$ Reed Nieman, ${ }^{a}$ Mona Goli, ${ }^{a}$ Wenjing Peng, ${ }^{a}$ Ahmed Hussein, ${ }^{\text {ab }}$ \\ Ercan Bursal, ${ }^{\mathrm{C}}$ Hans Lischka ${ }^{\text {ad }}$ and Yehia Mechref ${ }^{\mathbb{D}}$ *ae
}

Matrix-assisted laser desorption ionization-in source decay (MALDI-ISD) analysis is a useful technique in the structural analysis of glycans. Our recent publication demonstrated that magnetic carbon nanoparticles (MCNPs), used as a MALDI co-matrix, significantly enhanced ISD efficiency for glycomic analysis by MALDI-TOF. In this study, MCNPs were used for the structural study of isomeric glycans. Results from the standard glycans confirmed easy distinction of positional and linkage isomers without the need for further derivatization of glycan molecules. Extensive glycosidic and cross-ring fragmented ions provided different fragment patterns for various glycan isomers. Core- and branch-fucosylated isomers were distinguished by several unique ions, and pseudo-MS ${ }^{3}$ data were used to recognize the fucosylated branch. Although no diagnostic fragment ion was observed for 2,3- and 2,6-linked sialic acid isomers, their MALDI-ISD patterns were found to be significantly different $(P<0.05)$. Furthermore, the method introduced in this study could not only be used for the identification of glycan isomers but has also proved effective for the isomeric structural confirmation of gangliosides. GD1a and GD1b gangliosides were easily distinguished by the diagnostic ion originated from GD1a, produced by $Z_{4 \alpha} Z_{2 \beta}$ cleavages. Moreover, liquid chromatography coupled with MALDI-TOF was applied to analyze $N$-glycan isomers derived from a pooled human blood serum sample, providing an alternative method of isomeric glycomic analysis of biological specimens.

Received 27th March 2019

Accepted 3rd June 2019

DOI: $10.1039 / c 9 r a 02337 b$

rsc.li/rsc-advances which is mainly caused by the existence of multiple isomers. The structural study of oligosaccharides is, therefore, an essential part of efforts to gain more profound insights into glycosylation. ${ }^{17}$

Among the variety of analytical methods that have been reported for glycan analysis, mass spectrometry (MS) is considered one of the most prominent methods for glycan profiling. ${ }^{18,19}$ When coupled with different separation techniques, including ion mobility mass spectrometry, ${ }^{20-23}$ capillary electrophoresis, ${ }^{24-26}$ porous graphitized carbon chromatography (PGC), ${ }^{17,27-32}$ hydrophilic liquid interaction chromatography (HILIC) ${ }^{33,34}$ and reverse phase chromatography, ${ }^{35} \mathrm{MS}$ is a robust tool for the analysis of isomeric glycan. Considering all of these techniques, matrix-assisted laser desorption ionization (MALDI) offers several advantages, including rapid analysis time, ease of operation, small sample size requirements, and the relative simplicity of spectral interpretation. ${ }^{36-38}$ However, the relatively low ionization efficiency in both positive and negative ion modes and the instability of sialylated structures are the principal disadvantages of MALDI-MS analysis and must be addressed to achieve sensitive glycan analysis.

Derivatization of glycans before MS characterization offers advantages such as the stabilization of sialic acids and enhanced sensitivity and can be used to facilitate isomeric

$\dagger$ Electronic supplementary information (ESI) available. See DOI: $10.1039 / \mathrm{c} 9 \mathrm{ra02337b}$ 
analysis of glycans. ${ }^{39-43}$ For instance, Alley and Novotny ${ }^{39}$ investigated sialic acid linkage isomers in breast cancer patients using amidation before permethylation, resulting in separation of the two isomers with $13 \mathrm{~m} / \mathrm{z}$ unit per sialic acid residue. Later, Wuhrer et $a .^{43}$ introduced a method for linkage-specific sialic acid derivatization, where the carboxylic group of $\alpha 2,6$-linked sialic acids experienced ethyl esterification while $\alpha 2,3$-linked sialic acids formed a lactone with the neighboring galactose. More than $100 \mathrm{~N}$-glycans compositions with specific sialic acid linkages were detected using a MALDI-MS analysis of a human blood serum sample. However, derivatization introduced additional sample preparation steps, which may have increased deviation and sample loss.

Although MALDI is considered a soft-ionization technique, its ionization process could lead to the in-source decay (ISD) fragmentation of analytes, thus complicating the spectra. Although this phenomenon makes interpretation of spectra more difficult in some cases, it is nevertheless helpful for glycan profiling and structural identification. ${ }^{44-49}$ ISD fragmentation also has the potential to perform pseudo-MS ${ }^{3}$ experiments on MALDI. The amplitude of ISD fragmentation is dependent on matrix material and laser intensity. By controlling these parameters, ISD fragmentation in MALDI analysis can be used for the identification and relative quantification of glycan structures. Pauw et al. $^{44}$ used 5-nitrosalicylic acid (5-NSA) as an oxidizing matrix to improve ISD of glycans via radical formation of precursors. Glycosidic and cross-ring cleavages were promoted by hydrogen abstraction from the hydroxyl group of glycans by 5-NSA molecules. As an example of the effect of laser intensity on the amplitude of ISD fragmentation, whereas the low abundance of ISD ions was observed in the mass spectrometer equipped with a conventional laser power ( $\mu \mathrm{J}$ levels), using a higher laser power (50 mJ per pulse) produced extensive glycosidic and cross-ring fragmentations. ${ }^{49}$

In recent years, the importance of nanomaterials as outstanding MALDI matrices has become increasingly evident due to their unique physicochemical characteristics, such as excellent optical absorption, exceptional electrical properties, and low background interference. ${ }^{50-57}$ Among these materials, carbon-based nanomaterials such as carbon nanotubes, ${ }^{58}$ carbon nanodots, ${ }^{59,60}$ carbon nanoparticles (CNPs), ${ }^{50,61}$ and graphene nanosheets $(\mathrm{GNs})^{\mathbf{5 0 , 6 2 , 6 3}}$ have attracted the most attention. Compared to traditional organic matrices, these nanomaterials facilitate the desorption process and enhance MS signal intensity due to their superior interaction with biomolecules and efficient energy absorption.

Recently, we investigated the performance of CNPs, GNs, and magnetic CNPs (MCNPs) as MALDI matrices or co-matrices for glycan profiling of different model glycoproteins and human blood serum samples. ${ }^{\mathbf{5 0 , 6 1}}$ The material showed excellent absorption and transfer of laser energy to glycans, resulting in improved signal intensities by several orders of magnitude. Extensively-producing glycosidic and cross-ring cleavages, with the ability to easily control the extent of ISD fragmentation by changing the amount of nanomaterials in MALDI spot, confirmed the capability of these materials in the structural study of glycans.
In this study, MCNPs were used as a MALDI co-matrix for the isomeric study of glycans derived from a human blood serum sample. The use of MCNPs-MALDI-TOF for the identification of glycan isomers was initially demonstrated using both positional and linkage glycan isomer standards and then performed on human blood serum to measure its application on complex biological samples. Moreover, the capability of an MCNPs comatrix for ganglioside isomer identification was also investigated. The glycan/glycolipid isomeric analysis enabled by the use of MCNPs as MALDI co-matrix facilitate rapid and straightforward analysis of glycans and glycolipids without the need for derivatization.

\section{Experimental section}

\section{Materials}

Standard $N$-glycans $\left(\mathrm{N}_{4} \mathrm{H}_{4} \mathrm{~F}_{1}, \mathrm{~F}_{1} \mathrm{~N}_{4} \mathrm{H}_{4}, \quad \mathrm{~N}_{4} \mathrm{H}_{4} \mathrm{~F}_{1} \mathrm{~S}_{1}, \quad \mathrm{~F}_{1} \mathrm{~N}_{4} \mathrm{H}_{4} \mathrm{~S}_{1}\right.$, $\mathrm{N}_{4} \mathrm{H}_{4} \mathrm{~F}_{1} \mathrm{~S}_{1}(2,3)$, and $\mathrm{N}_{4} \mathrm{H}_{4} \mathrm{~F}_{1} \mathrm{~S}_{1}(2,6)$; Table $\left.1 \mathrm{~S} \dagger\right)$ were purchased from Chemily Glycoscience (Atlanta, GA). Standard gangliosides (GD1a-bovine brain and GD1b-human brain) were purchased from Merck (Germany). Carbon nanoparticles (CNPs) (particle size less than $100 \mathrm{~nm}$ and specific surface area higher than 100 $\mathrm{m}^{2} \mathrm{~g}^{-1}$ ), blood serum from human male AB plasma, 2,5-dihydroxybenzoic acid (DHB), and borane-ammonia complex were purchased from Sigma-Aldrich (St. Louis, MO). PNGase F was obtained from New England Biolabs (Ipswich, MA). HPLC grade ethanol, acetonitrile (ACN), and water were used for sample preparation and were purchased from Sigma-Aldrich (St. Louis, $\mathrm{MO}$ ). MCNPs were readily synthesized by mixing $\mathrm{CNPs}, \mathrm{FeCl}_{3}$ $\cdot 6 \mathrm{H}_{2} \mathrm{O}$, and $\mathrm{FeCl}_{2} \cdot 4 \mathrm{H}_{2} \mathrm{O}$ at $50{ }^{\circ} \mathrm{C}$ under $\mathrm{N}_{2}$ atmosphere, as per our recently published paper. ${ }^{61}$

\section{Sample preparation methods}

Standard $N$-glycans and gangliosides were used directly without future purification. $N$-Glycans were released from human blood serum using PNGase F enzyme. ${ }^{31,32,64}$ Briefly, $40 \mu \mathrm{l}$ of $10 \times$ diluted denaturation buffer was mixed with $10 \mu \mathrm{l}$ aliquot of human blood serum (stock solution). After denaturation in a water bath at $80{ }^{\circ} \mathrm{C}$ for 30 minutes, $0.5 \mu$ l of PNGase F stock solution (500 units $\mu \mathrm{l}^{-1}$ ) was added, and the solution was incubated in a $37^{\circ} \mathrm{C}$ water bath for 18 hours. Proteins were then precipitated by the addition of $90 \%$ ethanol, followed by incubation at $-20{ }^{\circ} \mathrm{C}$ for 30 minutes. Purified glycans were reduced by adding a $10 \mu \mathrm{l}$ aliquot of freshly prepared ammonia borane solution $\left(10 \mu \mathrm{g} \mu \mathrm{l}^{-1}\right)$ to the dry sample, followed by incubation in $60{ }^{\circ} \mathrm{C}$ water bath for one hour.

\section{Instrument methods}

A MALDI TOF/TOF analyzer (AB SCIEX-4800), equipped with a pulsed Nd:YAG laser at an excitation wavelength of $355 \mathrm{~nm}$, was used for MALDI-MS analyses. For matrix preparation, $1 \mu \mathrm{l}$ of MCNPs suspension $\left(0.2 \mu \mathrm{g} \mu \mathrm{l}^{-1}, 50 \%\right.$ ACN : $\left.\mathrm{H}_{2} \mathrm{O}\right)$ was mixed with $1 \mu \mathrm{l}$ of DHB $\left(20 \mu \mathrm{g} \mu \mathrm{l}^{-1}, 50 \% \mathrm{ACN}: \mathrm{H}_{2} \mathrm{O}\right)$ to form a binary matrix. $1 \mu \mathrm{l}$ of the resulting mixture was added to the MALDI plate, followed by the addition of $0.5 \mu \mathrm{l}$ of the sample solution. The mass spectra were analyzed using Data Explorer 4.9 
software (AB SCIEX). GlycoWorkbench software was applied for MS data interpretation and glycoform analysis..$^{65}$ Domon and Costello nomenclature was employed to define the fragment ions from glycans. ${ }^{66}$

To study isomeric glycans derived from a human blood serum sample, an UltiMate 3000 nanoLC system (Thermo Scientific, Sunnyvale, CA) was used for LC separation, prior to the MALDI analyses. Porous graphitized carbon column (PGC, HyperCarb, $75 \mu \mathrm{m} \times 100 \mathrm{~mm}, 5 \mu \mathrm{m}$ particle size, Thermo Scientific, Pittsburgh, PA) was used for separation. ${ }^{17,67-69}$ Mobile phase A consisted of $50 \mathrm{mM}$ formic acid buffered to pH 3.0 with ammonia, and mobile phase $\mathrm{B}$ used acetonitrile. Reduced glycans were injected directly into the PGC column, with a flow rate of $0.5 \mu \mathrm{lmin}^{-1}$, and the gradient was as follows. In the first 15 minutes, mobile phase $\mathrm{B}$ was kept at $2 \%$; from 15 to 100 minutes, the percentage of B was increased to $30 \%$. Solvent B was further elevated from $30 \%$ to $45 \%$ in the following 20 minutes and finally increased to $80 \%$ for 5 minutes. It was maintained at $80 \%$ B for 15 minutes to elute highly sialylated glycans and finally quickly back to $2 \% \mathrm{~B}$. The outlet of the LC column was coupled to an LTQ Orbitrap Velos mass spectrometer (Thermo Scientific, San Jose, CA) through a nanoESI source with a $1.6 \mathrm{kV}$ ESI voltage. For off-line MALDI analyses, the liquid was collected every 30 seconds from the outlet of the column on the MALDI plate, which was already spotted by matrix materials.

\section{Molecular modeling}

Quantum chemistry calculations were performed to optimize the 3D structures of the core- and branch-fucosylated $N$-glycan isomers, $\mathrm{F}_{1} \mathrm{~N}_{4} \mathrm{H}_{4}$ and $\mathrm{N}_{4} \mathrm{H}_{4} \mathrm{~F}_{1}$, and the $\alpha 2,3-$ and $\alpha 2,6$-linked sialic acid isomers in order to better understand the mass spectra of such isomers. The 3D starting structures were generated using the GLYCAM-Web Carbohydrate Builder tool (http://www.glycam.org). ${ }^{70}$ Density functional theory (DFT) was then used to optimize the structures without inclusion of environmental effects by way of the Becke, 3-Parameter, LeeYang-Parr (B3LYP) hybrid functional ${ }^{71}$ with the split valence polarization (SVP) basis set, ${ }^{72}$ and the multipole-accelerated resolution of the identity for the Coulomb energy (MARI-J) approach. ${ }^{73}$ Empirical dispersion corrections were added by means of the D3 method. ${ }^{74}$ All calculations were carried out for the isolated molecules utilizing the Turbomole program suite. ${ }^{75}$
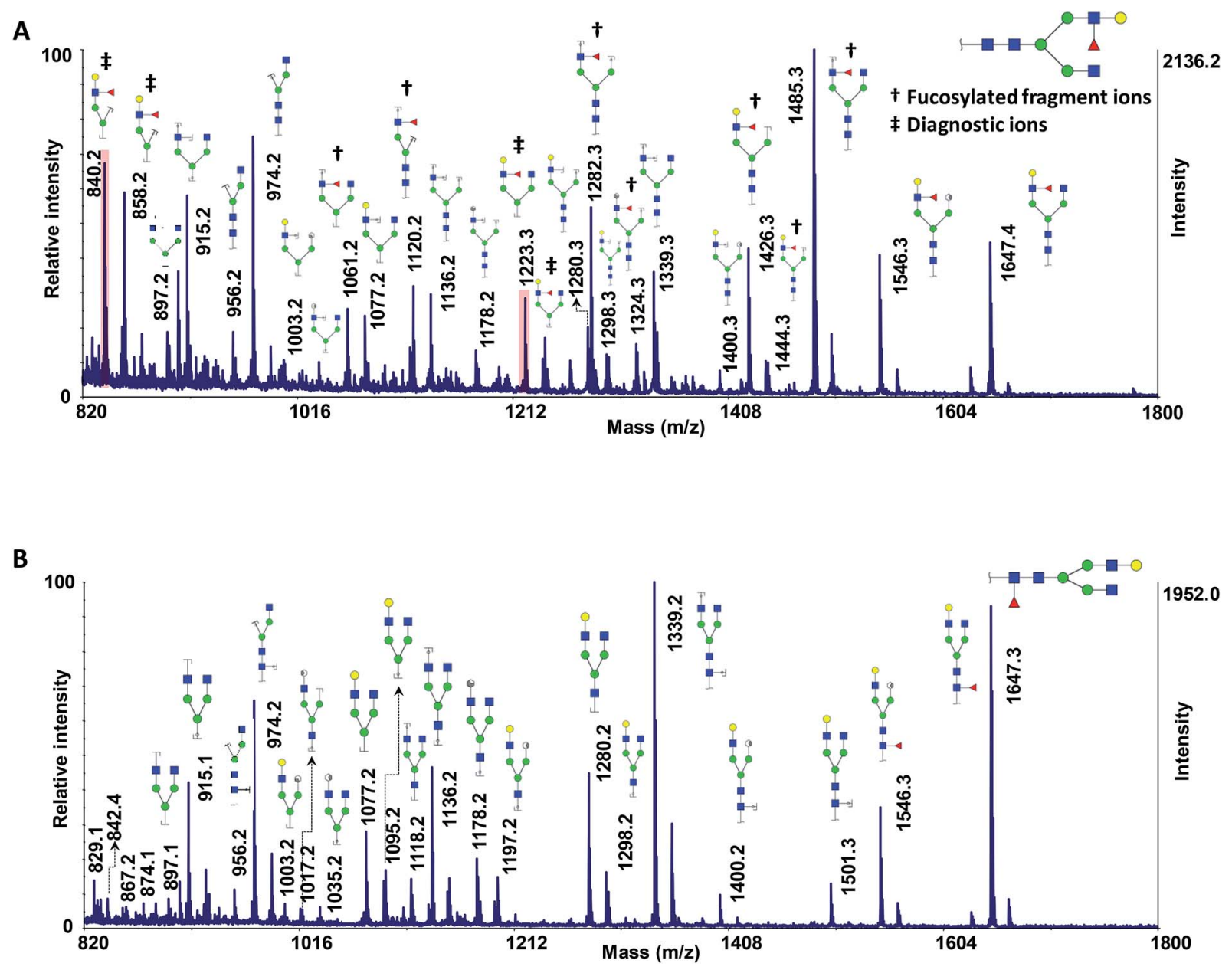

Fig. 1 MALDI-TOF-MS spectra of $50 \mathrm{ng}$ of (A) $\mathrm{N}_{4} \mathrm{H}_{4} \mathrm{~F}_{1}$ and (B) $\mathrm{F}_{1} \mathrm{~N}_{4} \mathrm{H}_{4}$, using $10 \mu \mathrm{g}$ DHB $+0.1 \mu \mathrm{g}$ MCNPs. Highlights show the ISD fragment ions that were selected for pseudo-MS ${ }^{3}$ analysis. $\uparrow$ shows the fucosylated fragment ions; $\$$ shows the diagnostic ions. Symbols: $\square, N$-acetylglucosamine; $O$, galactose; $\nabla$, fucose; $O$, mannose; $\diamond, N$-acetylneuraminic acid. 


\section{Results and discussion}

\section{MALDI-TOF-MS spectra of standard $\mathrm{N}$-glycans using MCNPs as a co-matrix}

We recently investigated the performance of using MCNPs as a MALDI matrix and co-matrix in glycan profiling. ${ }^{61}$ MCNPs not only enhanced the signal intensities by several orders of magnitude but also prompted ISD fragmentations, which produced extensive glycosidic and cross-ring cleavages. Interestingly, the extent of ISD fragmentation can be modulated by MCNPs concentrations to easily obtain $\mathrm{MS}^{2}$ and pseudo-MS ${ }^{3}$ spectra, which are beneficial in glycan profiling and structural identification.

To test the applicability of the MCNPs in the structural analysis of glycans, they were used as a co-matrix for analysis of coreand branch-fucosylated $\mathrm{N}$-glycan isomers. Fig. 1 shows the MALDI-TOF-MS spectra of $\mathrm{N}_{4} \mathrm{H}_{4} \mathrm{~F}_{1}$ (Fig. 1A) and $\mathrm{F}_{1} \mathrm{~N}_{4} \mathrm{H}_{4}$ (Fig. 1B) with all corresponding structures represented as illustrations. In comparison with DHB as a matrix (Fig. 1S $\dagger$ ), extensive glycosidic and cross-ring cleavages were produced by ISD fragmentations when MCNPs were utilized as a co-matrix. Significant differences between the spectra of the two isomers can be observed. Four fragment ions, indicated by a double dagger in Fig. $1 \mathrm{~A}$, at $\mathrm{m} / \mathrm{z}$ $840.2,858.2,1223.3$, and 1239.3 are the diagnostic ions of $\mathrm{N}_{4} \mathrm{H}_{4} \mathrm{~F}_{1}$. The ions at $m / z 1223.3\left(\mathrm{C}_{4 \alpha}\right)$ and $1239.3\left(\mathrm{~B}_{4 \alpha}\right)$ were generated by cleaving two GlcNAc, and the ions at $\mathrm{m} / \mathrm{z} 840.2$ $\left(\mathrm{C}_{4 \alpha} \mathrm{C}_{1 \beta}\right)$ and $858.2\left(\mathrm{C}_{4 \alpha} \mathrm{B}_{1 \beta}\right)$ originated by losing three GlcNAc. In addition to these diagnostic ions, there are seven fragment ions found only in the spectrum of $\mathrm{N}_{4} \mathrm{H}_{4} \mathrm{~F}_{1}$ (indicated by a dagger in Fig. 1A). These ions were observed at $m / z$ 1061.2, 1120.2, 1282.3,
1324.3, 1426.3, 1444.3, and 1485.3 and are fucosylated fragment ions. In contrast, the fragment ion produced by fucose cleavage, at $m / z$ 1501.3, appeared only in MALDI-ISD of $\mathrm{F}_{1} \mathrm{~N}_{4} \mathrm{H}_{4}$ (Fig. 1B). The results illustrate that the loss of fucose was suppressed when the fucose was located on the branch.

To confirm these data, the structures of both isomers were optimized by computer modeling, performed as described above. As can be seen in Fig. 2, when the fucose is located on the branch, the molecule is more compact, and the fucose is closer to the surrounding monosaccharides, thus possibly increasing bond energy. The bond dissociation energies $\left(\Delta E, \mathrm{kcal} \mathrm{mol}^{-1}\right)$ for the fucose loss were calculated as 120.3 and 110.2 for the $\mathrm{N}_{4} \mathrm{H}_{4} \mathrm{~F}_{1}$ and $\mathrm{F}_{1} \mathrm{~N}_{4} \mathrm{H}_{4}$ respectively, illustrating that higher energy is needed for the fragmentation of fucose when it is located on the branch.

The relative intensities of the fragment ions derived from the two isomers are compared in Fig. 3A, which illustrates significant differences $(P<0.05)$ between most of them. The relative intensity stability was tested using five selected peaks and the results are shown in Table $2 \mathrm{~S} . \dagger$ Moreover, five samples with different molar ratios of the two isomers were prepared, and the intensities of the fragment ions were compared. As an example, the intensities of the four peaks at $m / z 840.2,1223.3,1426.3$ and 1485.3 are shown in Fig. 3B. Increasing their intensities by increasing the molar ratio of $\mathrm{N}_{4} \mathrm{H}_{4} \mathrm{~F}_{1}$ in the mixture confirmed that these ions originated from $\mathrm{N}_{4} \mathrm{H}_{4} \mathrm{~F}_{1}$.

As discussed above, ISD fragmented ions can be employed to produce pseudo-MS ${ }^{3}$ spectra that can provide valuable data for structural identification. The applicability of the proposed matrix for pseudo-MS ${ }^{3}$ analysis was investigated on the peaks at
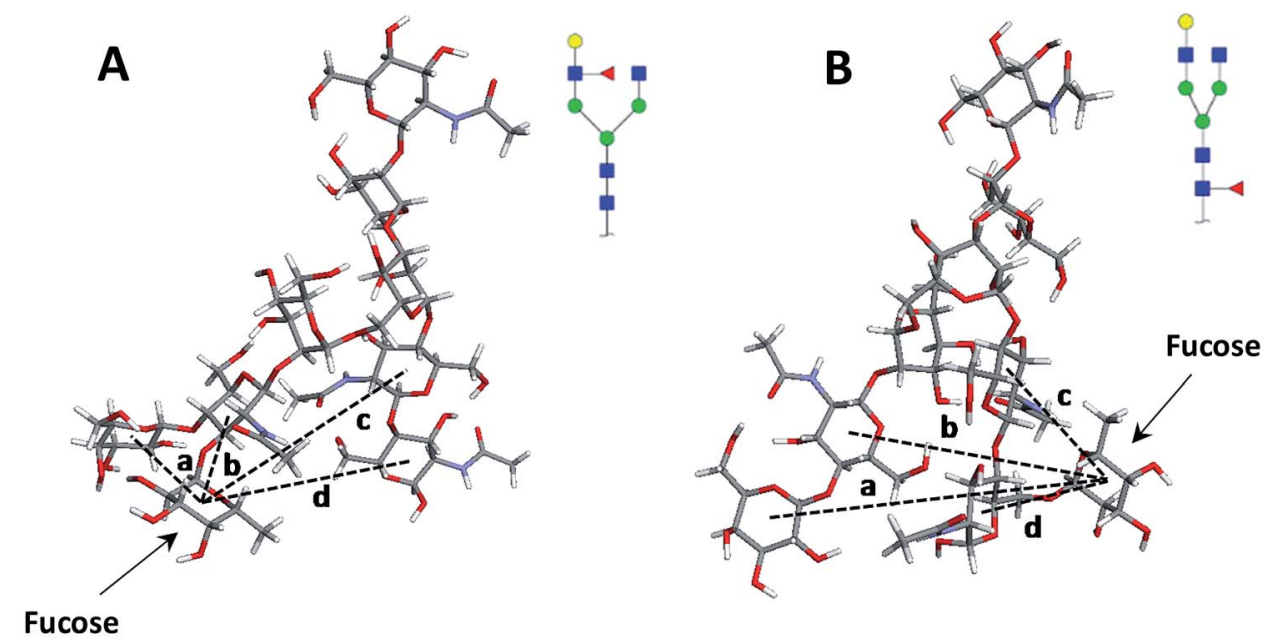

\begin{tabular}{|l|c|c|c|c|}
\hline $\begin{array}{l}\text { The distances of the center of fucose with } \\
\text { the center of surrounding monosaccharides } \\
(\AA)\end{array}$ & $\mathbf{a ~}(\AA)$ & $\mathbf{b}(\AA)$ & $\mathbf{c}(\AA)$ & $\mathbf{d}(\AA)$ \\
\hline Branched-fucosylated isomer & 5.4 & 4.7 & 12.6 & 10.9 \\
\hline Core-fucosylated isomer & 14.8 & 11.9 & 5.4 & 6.1 \\
\hline
\end{tabular}

Fig. 2 The molecular modeling of $(A) N_{4} H_{4} F_{1}$ and (B) $F_{1} N_{4} H_{4}$ while the table summarizes the distance of the center of fucose with the center of surrounding monosaccharides. Symbols as in Fig. 1. 

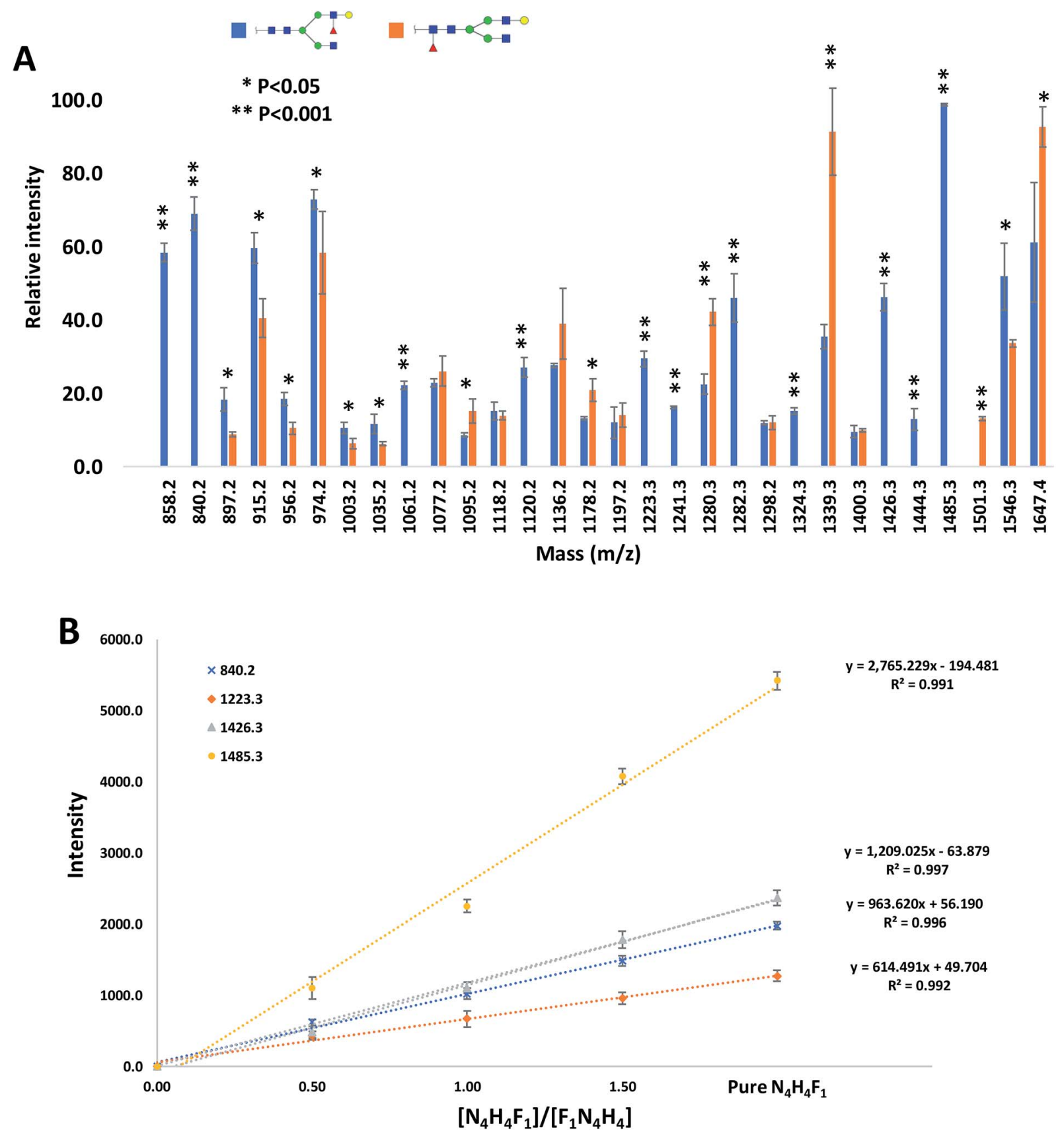

Fig. 3 (A) Comparison of the relative intensities of the fragment ions derived from $\mathrm{N}_{4} \mathrm{H}_{4} \mathrm{~F}_{1}$ and $\mathrm{F}_{1} \mathrm{~N}_{4} \mathrm{H}_{4}$. (B) The intensities of the four fragment ions derived from $\mathrm{N}_{4} \mathrm{H}_{4} \mathrm{~F}_{1}$ at different ratios of $\mathrm{N}_{4} \mathrm{H}_{4} \mathrm{~F}_{1}: \mathrm{F}_{1} \mathrm{~N}_{4} \mathrm{H}_{4}$. Symbols as in Fig. 1.

$\mathrm{m} / \mathrm{z} 840.2$ (Fig. 4A) and 1223.3 (Fig. 4B), which are diagnostic ions of $\mathrm{N}_{4} \mathrm{H}_{4} \mathrm{~F}_{1}$. Several ions corresponding to the fragmentation of the ions of interest were observed, with relatively high signal-to-noise ratios, an aspect beneficial for structural analysis. As an example, the fragments at $m / z 190.1$ (Fig. 4A) and 1020.1 (Fig. 4B) confirmed the linkage of the fucose to the GlcNAc on the $\alpha 1,3$-antennae of the $\mathrm{N}_{4} \mathrm{H}_{4} \mathrm{~F}_{1}$, which is a galactose-containing branch. The ion at $m / z 190.1$ is a fragment that contains one GlcNAc with three cleavage sites; the fragment ion at $\mathrm{m} / \mathrm{z} 1020.1$ contains four hexoses, one GlcNAc, and one fucose with two cleavage sites.
To further investigate the effect of fucose linkage in the ISD pattern, $\mathrm{N}_{4} \mathrm{H}_{4} \mathrm{~F}_{1} \mathrm{~S}_{1}$ (Fig. 2Sa $\dagger$ ) and $\mathrm{F}_{1} \mathrm{~N}_{4} \mathrm{H}_{4} \mathrm{~S}_{1}$ (Fig. 2Sb $\dagger$ ) were also analyzed. The results were comparable with the results obtained for $\mathrm{N}_{4} \mathrm{H}_{4} \mathrm{~F}_{1}$ and $\mathrm{F}_{1} \mathrm{~N}_{4} \mathrm{H}_{4}$ (Fig. 1); however, due to the labile sialyl linkage, weak signals were observed for the intact molecules. In addition to the peak at $\mathrm{m} / \mathrm{z} 1223.3$, a diagnostic ion for $\mathrm{N}_{4} \mathrm{H}_{4} \mathrm{~F}_{1} \mathrm{~S}_{1}$, again there are seven fucosylated fragment ions that appeared only in the spectrum of $\mathrm{N}_{4} \mathrm{H}_{4} \mathrm{~F}_{1} \mathrm{~S}_{1}$ (Fig. 2Sa $\dagger$ ), confirming that the loss of the fucose was suppressed when the fucose is located at the antenna. Significant differences $(P<0.05)$ were also observed between 




B

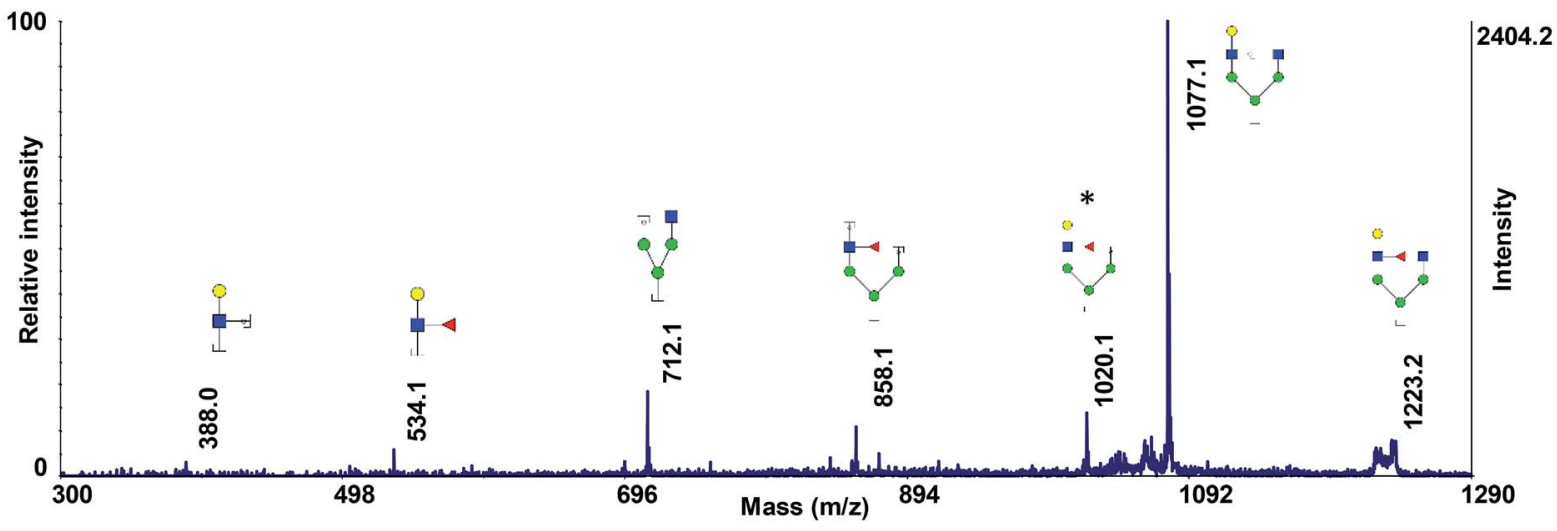

Fig. 4 Pseudo-MS ${ }^{3}$ spectra of the ISD fragment ions at $m / z$ (A) 840.2 and (B) 1223.2, as highlighted in Fig. 1. Symbols as in Fig. 1.

the relative intensities of most fragment ions originated by the two isomers (Fig. 2Sc $\dagger$ ). The data in Table $2 \mathrm{~S} \uparrow$ illustrates the relative intensity stability of the fragment ions originated by these two isomers. Further MCNPs was performed to distinguish sialylated linkage isomers. Glycan standard $\mathrm{N}_{4} \mathrm{H}_{5} \mathrm{~S}_{1}(2,3)$ and $\mathrm{N}_{4} \mathrm{H}_{5} \mathrm{~S}_{1}(2,6)$ were used for illustration, and the results are shown in Fig. 5A and B. Although no diagnostic ion was observed for these isomers, the distribution of their fragment ions was significantly different $(P<0.05)$, as shown in Fig. 5C. Moreover, a fragment ion at $m / z 1853.1$ appeared only in the spectrum of $\mathrm{N}_{4} \mathrm{H}_{5} \mathrm{~S}_{1}(2,6)$, which was originated by the cross-ring fragmentation of sialic acid $\left({ }^{2,4} \mathrm{X}\right)$. In comparison with the $\alpha 2,3$ isomer, the $\alpha 2,6$-linked sialic acid isomer shows significantly higher relative intensity for intact glycan $(\mathrm{m} / \mathrm{z}$ 1976.3), indicating higher stability of the glycosylic bond between the sialic acid and galactose. Moreover, comparing the relative intensities of the $\mathrm{Y}_{6 \alpha}$ fragment ions $(\mathrm{m} / \mathrm{z}$ 1663.3) derived from two isomers shows more energy is needed to lose galactose in an $\alpha 2,6$ isomer. This result was further supported by computer modeling data. The optimized geometries for the two isomers (Fig. 6) indicate that the $\alpha 2,6$-linked sialic acid isomer is more compact and the sialic acid residue is closer to the GlcNAc. The bond dissociation energies (Table $3 \mathrm{~S} \dagger$ ) illustrate that higher energy is needed for sialic acid and galactose loss in the $\alpha 2,6$-linked sialic acid isomer. The relative intensity stability of the fragment ions derived from these two isomers confirmed by the data in Table $2 \mathrm{~S} . \dagger$

\section{MALDI-TOF-MS spectra of standard gangliosides using MCNPs as a co-matrix}

Gangliosides are sialic acid-containing glycosphingolipids which are found in tissues and body fluids, with more abundance in the nervous system. They are associated with different mammalian diseases including lung, breast, prostate, and ovarian cancer as well as brain tumors, and therefore the reliable identification of ganglioside isomers is important for biomarker discovery studies. ${ }^{76-79}$ To date, more than 180 ganglioside species with different glycan headgroups have been identified in vertebrate tissues.

The performance of the MCNPs as a MALDI co-matrix in the structural analysis of isomeric gangliosides was also investigated, using ganglioside isomers GD1a and GD1b. These two isomers differ in the linkage of sialic acid. ${ }^{76,77}$ The MALDI-ISD spectra of the two isomers are shown in Fig. 7A and $\mathrm{B}$. The peaks at $\mathrm{m} / \mathrm{z} 1931.5$ indicate the intact gangliosides, which were detected as $[\mathrm{M}+3 \mathrm{Na}-2 \mathrm{H}]^{+}$. For both isomers, another peak can be seen with 28 Da mass difference $(m / z$ 1903.5), which was originated by the difference in 
A
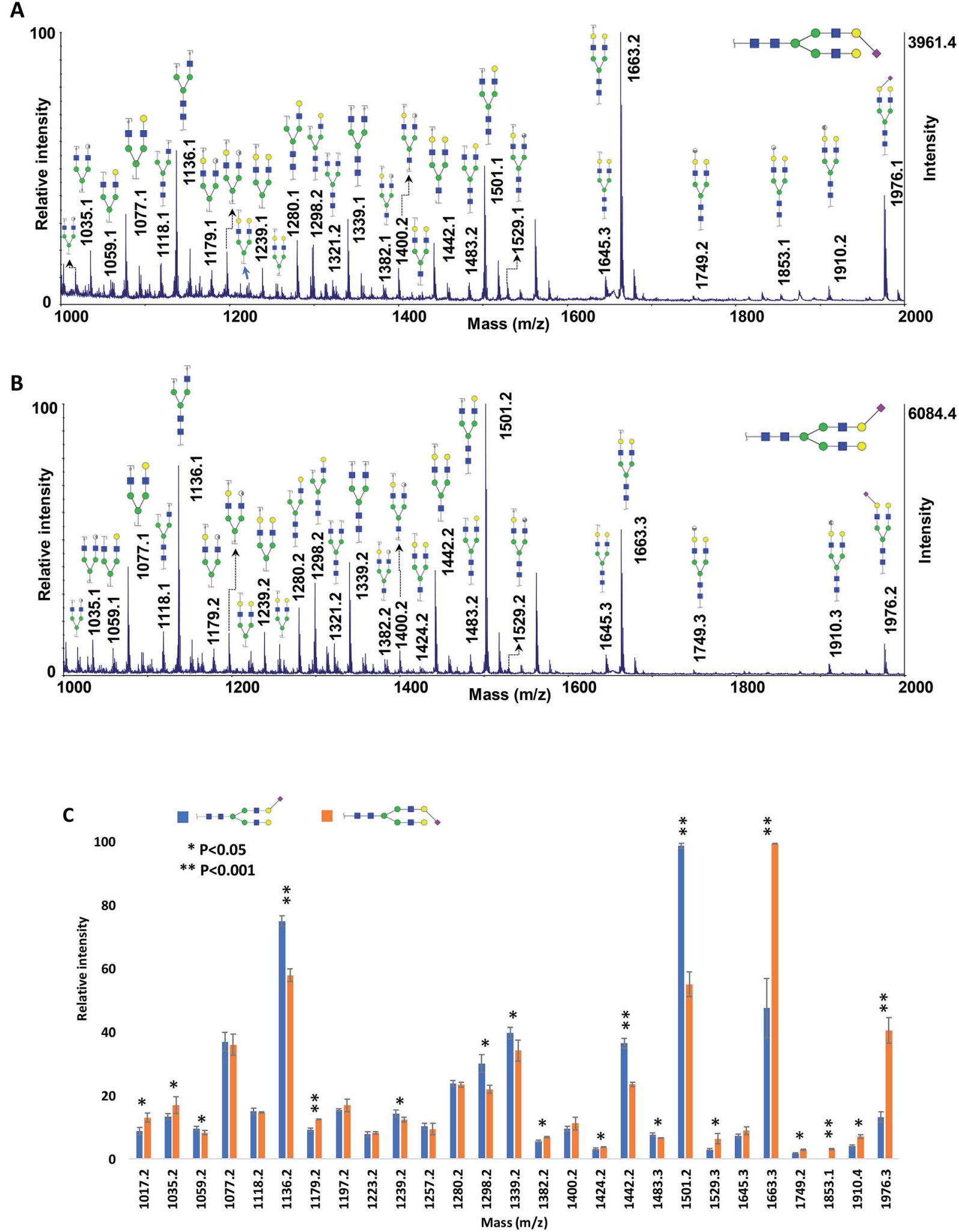

Fig. 5 MALDI-TOF-MS spectra of $50 \mathrm{ng}$ of (A) $\mathrm{N}_{4} \mathrm{H}_{5} \mathrm{~S}_{1}(2,6)$ and (B) $\mathrm{N}_{4} \mathrm{H}_{5} \mathrm{~S}_{1}(2,3)$, using $10 \mu \mathrm{D} \mathrm{DHB}+0.1 \mu \mathrm{g}$ MCNPs. (C) Comparison of the relative intensities of the fragment ions derived from $\mathrm{N}_{4} \mathrm{H}_{5} \mathrm{~S}_{1}(2,6)$ and $\mathrm{N}_{4} \mathrm{H}_{5} \mathrm{~S}_{1}(2,3)$. Symbols as in Fig. 1.

the lengths of the lipid moieties. The same peaks with $28 \mathrm{Da}$ mass difference can also be observed for all of the fermented ions.
The spectra show dominant glycosidic cleavages leading to $\mathrm{Y}$ ions and a few low abundant $\mathrm{Z}$ ions. No cleavage was observed on the lipid moieties. Although most of the 
A

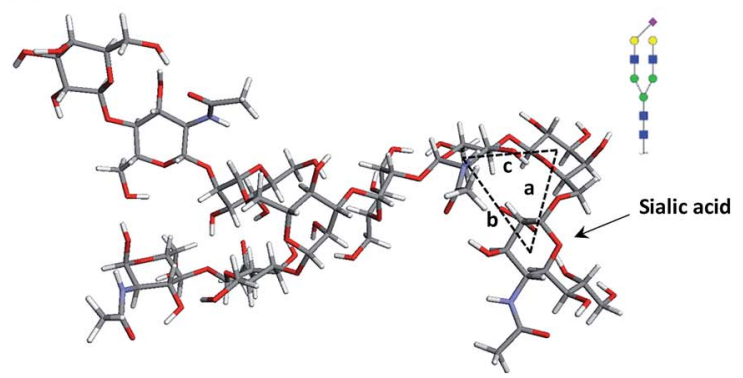

B

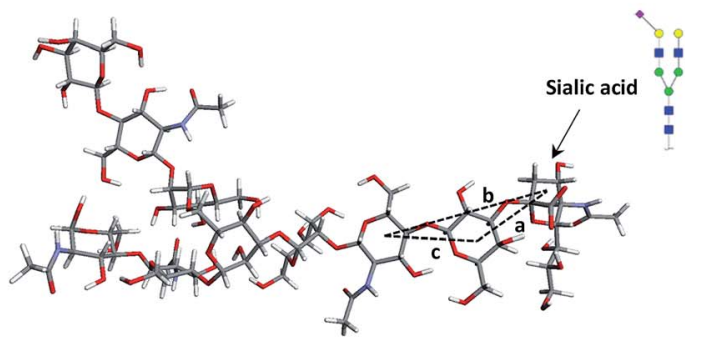

\begin{tabular}{|l|c|c|c|}
\hline $\begin{array}{l}\text { The distances of the center of sialic acid with } \\
\text { the center of surrounding monosaccharides }(\AA)\end{array}$ & $\mathbf{a}(\AA)$ & $\mathbf{b}(\AA)$ & $\mathbf{c}(\AA)$ \\
\hline$\alpha 2,6$-linked sialic acid isomer & 6.5 & 6.6 & 5.3 \\
\hline$\alpha 2,3$-linked sialic acid isomer & 5.2 & 10.6 & 5.6 \\
\hline
\end{tabular}

Fig. 6 The molecular modeling of $(A) \mathrm{N}_{4} \mathrm{H}_{5} \mathrm{~S}_{1}(2,6)$ and $(B) \mathrm{N}_{4} \mathrm{H}_{5} \mathrm{~S}_{1}(2,3)$ while the table summarizes the distance of the center of sialic acid with the center of surrounding monosaccharides. Symbols as in Fig. 1.

fragment ions are common between the two isomers, the ion at $m / z 1269.6$ (Fig. 7A) is the diagnostic ion of GD1a, which was produced by $\mathrm{Z}_{4 \alpha} \mathrm{Z}_{2 \beta}$ cleavages. Moreover, Fig. 7C exhibited significant alterations of fragment distributions between the two isomers, suggesting the proposed matrix can be utilized in the structural analysis of ganglioside isomers.

Use of MCNPs as a MALDI co-matrix in the isomeric study of glycans derived from human blood serum

The utility of MCNPs was then investigated in the glycomic study of $\mathrm{N}$-glycans derived from human blood serum. Human blood serum contains proteins with sophisticated glycosylation, and its profiling plays an essential role in biomarker discovery, and disease diagnosis and prognosis. ${ }^{7,16,18,80,81}$ Isomers of reduced glycans were first separated by a PGC-nanoLC system and then analyzed with MALDI using MCNPs as a co-matrix. Reduced glycans were used to prevent anomeric separation on the PGC column. Fig. 8A shows the extracted ion chromatogram (EIC) of $\mathrm{N}_{4} \mathrm{H}_{4} \mathrm{~F}_{1}^{*}\left(\mathrm{~F}^{*}\right.$ : denotes to both core- and branch-fucosylated isomers), and the corresponding MALDI spectra. As it can be observed, the patterns of the peaks in the MALDI spectra in Fig. $8 \mathrm{~B}$ and $\mathrm{C}$ are identical to the results that were obtained for the branch- and core-fucosylated standard isomer, respectively. In addition to the peak at $\mathrm{m} / \mathrm{z} 1223.3$ (the diagnostic ion of $\mathrm{N}_{4} \mathrm{H}_{4} \mathrm{~F}_{1}$ ), fucosylated fragment ions can only be observed for this isomer. These results confirmed that the peaks at $43.6 \mathrm{~min}$ and $44.7 \mathrm{~min}$ represent $\mathrm{N}_{4} \mathrm{H}_{4} \mathrm{~F}_{1}$ and $\mathrm{F}_{1} \mathrm{~N}_{4} \mathrm{H}_{4}$, respectively.

Fig. $3 \mathrm{~S} \uparrow$ shows the EIC and the corresponding MALDI spectra of the sialic acid-linked isomers of $\mathrm{N}_{4} \mathrm{H}_{4} \mathrm{FS}_{1}$. Two peaks were observed at retention times 46.3 and 51.8 min (Fig. 3Sa†).
Fig. $3 \mathrm{Sb} \uparrow$ depicts the MALDI spectrum of the peak eluting at $46.3 \mathrm{~min}$, while Fig. $3 \mathrm{Sc} \dagger$ represents the MALDI spectrum of the second peak eluting at $51.8 \mathrm{~min}$. The pattern of the peaks in Fig. $3 \mathrm{Sb} \dagger$ is coincident with the results that were obtained for the $\alpha 2,6$-linked sialic acid structure, with higher relative intensities for the intact structure $\left(m / z\right.$ 1978.4) and the $\mathrm{Y}_{6 \alpha}$ fragment ion $(\mathrm{m} / \mathrm{z}$ 1665.4). A similar pattern to that of the $\alpha 2,3$-linked sialic acid structure can be seen in Fig. $3 \mathrm{Sc}, \dagger$ with a higher relative intensity for the $Y_{5 \alpha}$ fragment ion $(\mathrm{m} / z$ 1503.2). The results confirmed that the peaks at 46.3 and 51.8 represent $\mathrm{N}_{4} \mathrm{H}_{5} \mathrm{~S}_{1}(2,6)$ and $\mathrm{N}_{4} \mathrm{H}_{5} \mathrm{~S}_{1}(2,3)$ structures, respectively. These results are compatible with the previously reported data for $\mathrm{N}$ glycans derived from human blood serum samples, where the significantly higher relative intensity of the $\alpha 2,6$ isomer was shown..$^{82,83}$

The EIC of the four isomers of $\mathrm{N}_{4} \mathrm{H}_{5} \mathrm{~S}_{2}$ and their corresponding MALDI spectra are shown in Fig. 9. Similar to the results that were obtained for monosialylated glycans, the relative intensities of the $\mathrm{Y}_{6 \alpha} \mathrm{Y}_{6 \beta}$ and $\mathrm{Y}_{5 \alpha} \mathrm{Y}_{6 \beta}$ fragment ions are dependent upon the sialic acid linkage. The peaks in the EIC were assigned by comparison with the relative intensities of the $\mathrm{Y}_{6 \alpha} \mathrm{Y}_{6 \beta}$ and $\mathrm{Y}_{5 \alpha} \mathrm{Y}_{6 \beta}$ fragment ions in the MALDI-ISD spectra. As can be seen in Fig. 9B and C, for the structures with two $\alpha 2,6$ - and $\alpha 2,3$-linked sialic acids, $\mathrm{Y}_{6 \alpha} \mathrm{Y}_{6 \beta}$, and $\mathrm{Y}_{5 \alpha} \mathrm{Y}_{6 \beta}$ fragment ions show higher relative intensities, respectively. For the other two isomers at 49.6 and $54.8 \mathrm{~min}$, with one $\alpha 2,6-$ and $\alpha 2,3$-linkage in their structures, similar relative intensities were obtained for $\mathrm{Y}_{6 \alpha} \mathrm{Y}_{6 \beta}$ and $\mathrm{Y}_{5 \alpha} \mathrm{Y}_{6 \beta}$ fragment ions (Fig. 9C and D). Although more work needs to be done to improve separation efficiency prior to MALDI measurements and therefore the assignment of more structures, these data illustrate the applicability of our proposed matrix to easily distinguish both positional and linkage isomers derived from 

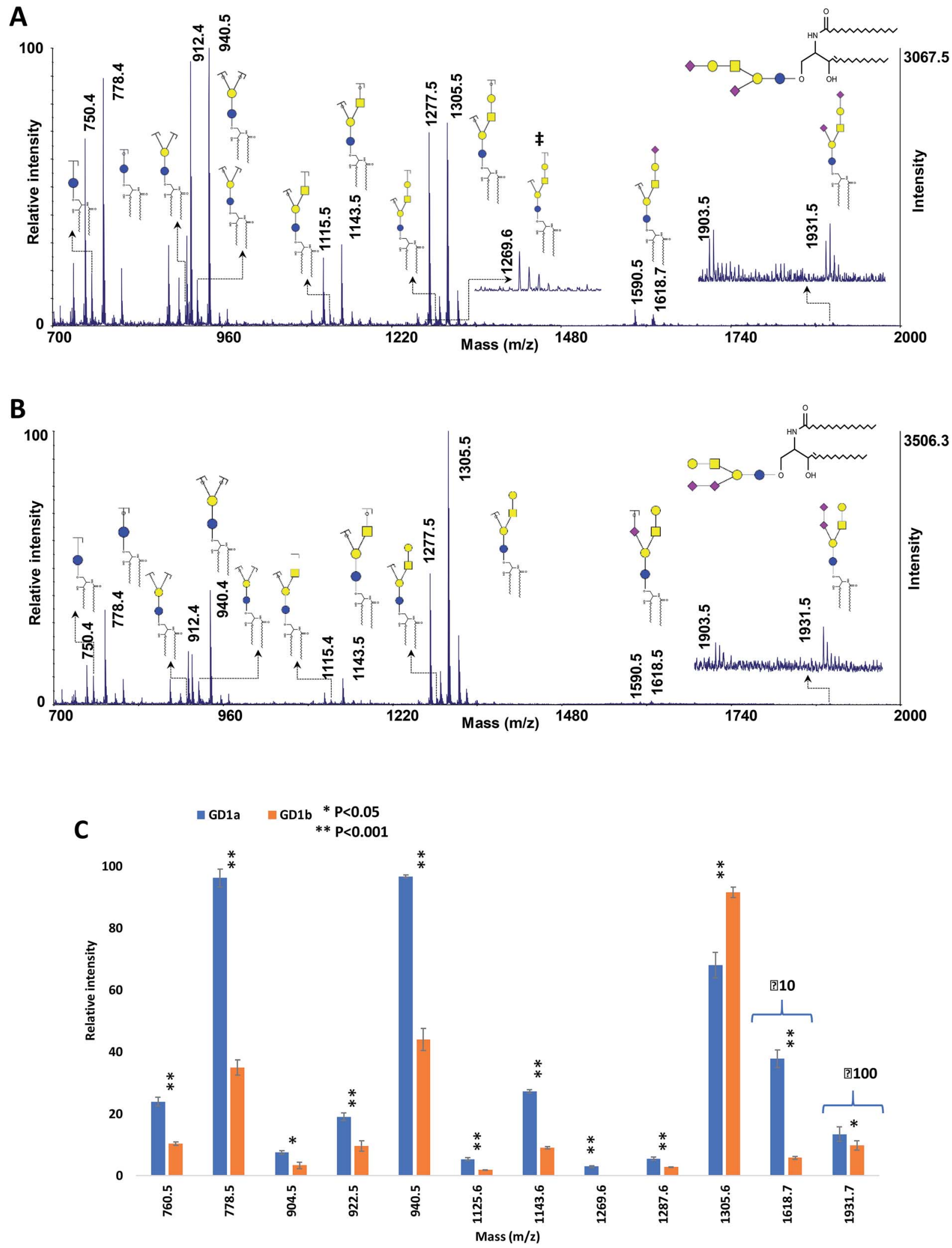

Fig. 7 MALDI-TOF-MS spectra of $100 \mathrm{ng}$ of ganglioside isomers (A) GD1a and (B) GD1b, using $10 \mu \mathrm{g}$ DHB $+0.1 \mu \mathrm{g}$ MCNPs. (C) Comparison of the relative intensities of the fragment ions derived from GD1a and GD1b. $\$$ shows diagnostic ions. Symbols as in Fig. 1.

a complex biological sample. The effectiveness of the MCNPs as a co-matrix will be investigated in the future work by the analysis of $\mathrm{N}$ - and $\mathrm{O}$-glycans derived from different biological samples such as mice and porcine tissues, Medicago leaf, human urine, breast and brain cancer cell lines, and human salivary mucins. ${ }^{16,30,84-92}$ 


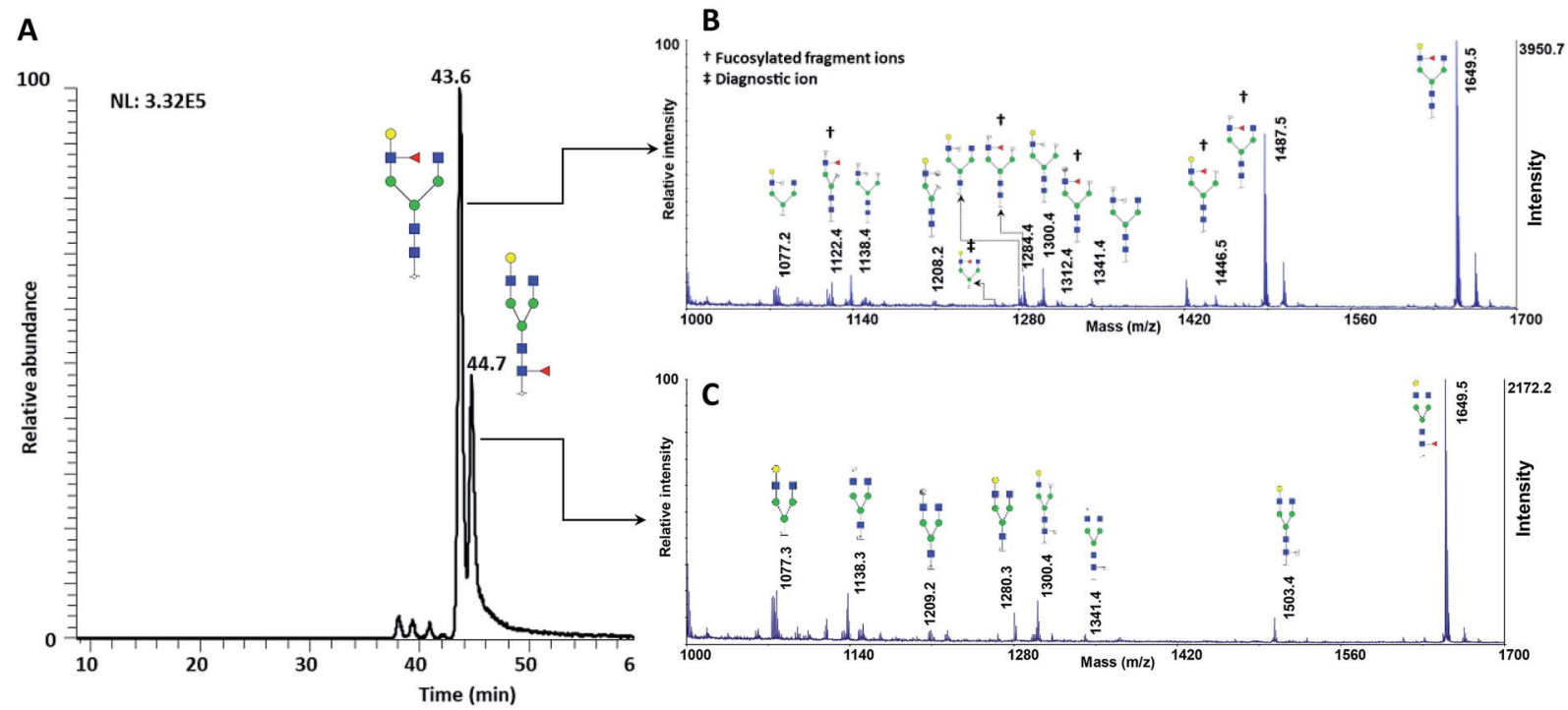

Fig. 8 (A) Extracted ion chromatogram of the glycan $\mathrm{N}_{4} \mathrm{H}_{4} \mathrm{~F}_{1}$, released from human blood serum. MALDI-TOF-MS spectra of the peak at (B) $43.2 \mathrm{~min}$ and (C) $44.7 \mathrm{~min}$. $\uparrow$ shows the fucosylated fragment ions, $\$$ shows the diagnostic ions. Symbols as in Fig. 1.

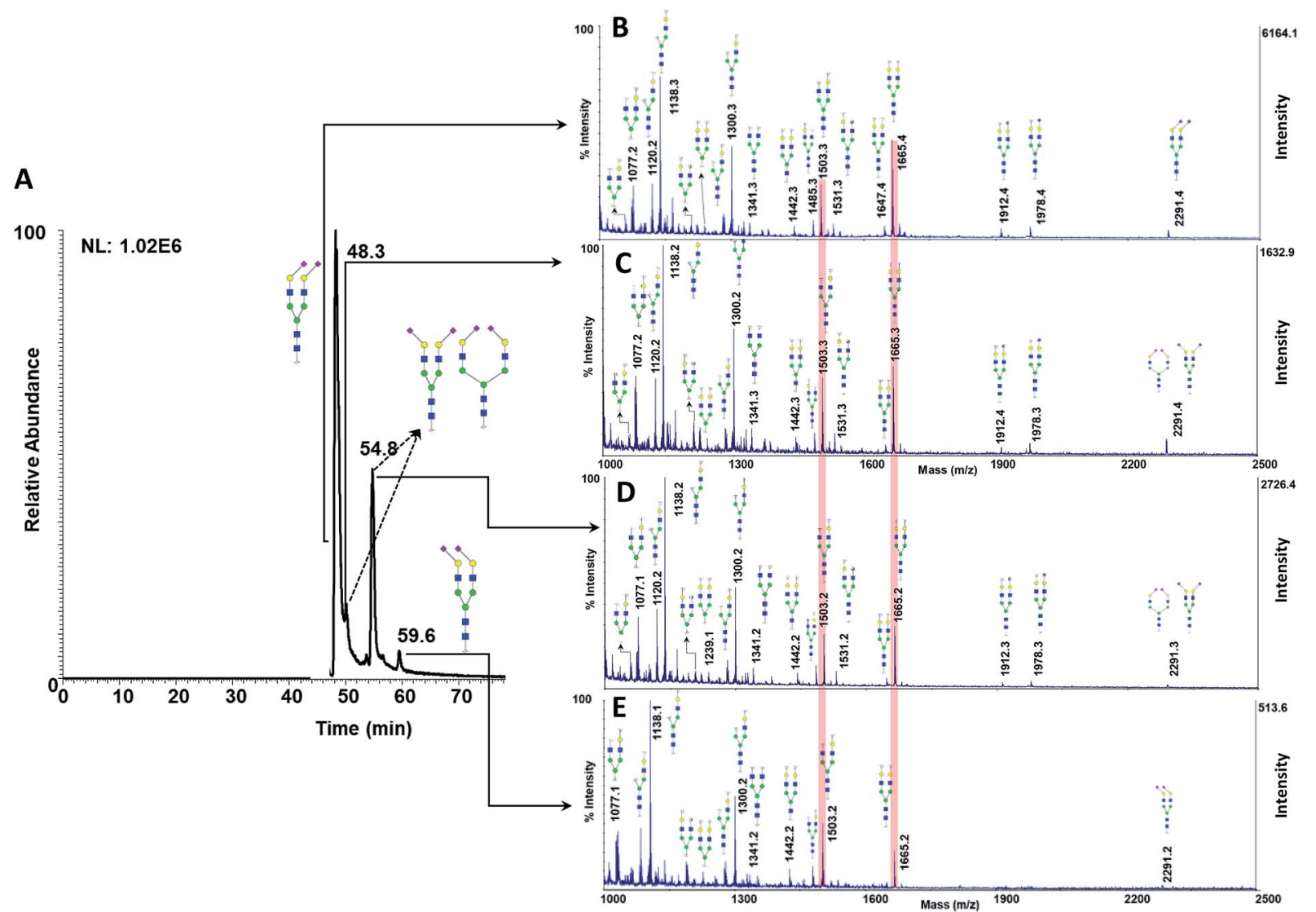

Fig. 9 (A) Extracted ion chromatogram of glycan $\mathrm{N}_{4} \mathrm{H}_{5} \mathrm{~S}_{2}$, derived from $0.5 \mu$ l of human blood serum. MALDI-TOF-MS spectra of the peak at (B) $48.3 \mathrm{~min},(C) 49.6 \mathrm{~min},(D) 54.8 \mathrm{~min}$, and (E) $59.6 \mathrm{~min}$. Highlights show the relative intensities of the $\mathrm{Y}_{6 \alpha} \mathrm{Y}_{6 \beta}$ and $\mathrm{Y}_{5 \alpha} \mathrm{Y}_{6 \beta}$ fragment ions, derived from the four isomers. Symbols as in Fig. 1.

\section{Conclusion}

In this work, MCNPs were used as a MALDI co-matrix for the structural study of isomeric glycans. The MALDI-ISD results demonstrated the ability of MCNPs to generate desired structural information. Extensive glycosidic and cross-ring bond fragmentations provided valuable data to distinguish both positional and linkage isomers. Data for standard glycans 
showed that, while core- and branch-fucosylated glycans were discriminated by their several unique ions, a significant difference between the relative intensities of the ISD fragmented ions helped to differentiate sialic acid linkage isomers. The applicability of MCNPs in the structural analysis of glycans was also confirmed by the analysis of ganglioside isomers. Although no cleavages occurred at the lipid moieties, the ISD of their headgroup glycans produced unique ions to distinguish these isomers. Finally, the use of PGC-LC to separate glycan isomers, prior to MALDI analyses, provided the facility for structural analysis of glycans derived from a human blood serum sample.

\section{Conflicts of interest}

The authors declare that they have no conflict of interest.

\section{Acknowledgements}

This work was supported by grants from National Institutes of Health, NIH (1R01GM112490-04, 1R01GM130091-01, and 1U01CA225753-01).

\section{References}

1 A. Helenius and M. Aebi, Science, 2001, 291, 2364-2369.

2 K. W. Moremen, M. Tiemeyer and A. V. Nairn, Nat. Rev. Mol. Cell Biol., 2012, 13, 448-462.

3 M. L. Bermingham, M. Colombo, S. J. McGurnaghan, L. A. Blackbourn, F. Vučković, M. P. Baković, I. TrbojevićAkmačić, G. Lauc, F. Agakov and A. S. Agakova, Diabetes Care, 2018, 41, 79-87.

4 A. V. Everest-Dass, E. S. Moh, C. Ashwood, A. M. Shathili and N. H. Packer, Expert Rev. Proteomics, 2018, 15, 165-182.

5 A. V. Everest-Dass, E. S. Moh, C. Ashwood, A. M. Shathili and N. H. Packer, Expert Rev. Proteomics, 2018, 15, 341-352.

6 Y. Kizuka, S. Kitazume and N. Taniguchi, Biochim. Biophys. Acta, Gen. Subj., 2017, 1861, 2447-2454.

7 W. Peng, J. Zhao, X. Dong, A. Banazadeh, Y. Huang, A. Hussien and Y. Mechref, Expert Rev. Proteomics, 2018, 15, 1007-1031.

8 A. C. Russell, M. Šimurina, M. T. Garcia, M. Novokmet, Y. Wang, I. Rudan, H. Campbell, G. Lauc, M. G. Thomas and W. Wang, Glycobiology, 2017, 27, 501-510.

9 S. Schedin-Weiss, B. Winblad and L. O. Tjernberg, FEBS J., 2014, 281, 46-62.

10 M. Van Scherpenzeel, E. Willems and D. J. Lefeber, Glycoconjugate J., 2016, 33, 345-358.

$11 \mathrm{H}$. Guo and K. L. Abbott, in Advances in cancer research, Elsevier, 2015, vol. 126, pp. 281-303.

12 M. J. Kailemia, D. Park and C. B. Lebrilla, Anal. Bioanal. Chem., 2017, 409, 395-410.

13 Y. Mechref, Y. Hu, A. Garcia and A. Hussein, Electrophoresis, 2012, 33, 1755-1767.

14 A. Mehta, H. Herrera and T. Block, in Advances in cancer research, Elsevier, 2015, vol. 126, pp. 257-279.

15 S. Pan, T. A. Brentnall and R. Chen, World J. Gastroenterol., 2016, 22, 9288-9299.
16 L. Veillon, C. Fakih, H. Abou-El-Hassan, F. Kobeissy and Y. Mechref, ACS Chem. Neurosci., 2018, 9, 51-72.

17 L. Veillon, Y. Huang, W. Peng, X. Dong, B. G. Cho and Y. Mechref, Electrophoresis, 2017, 38, 2100-2114.

18 X. Dong, Y. Huang, B. G. Cho, J. Zhong, S. Gautam, W. Peng, S. D. Williamson, A. Banazadeh, K. Y. Torres-Ulloa and Y. Mechref, Electrophoresis, 2018, 39, 3063-3081.

19 A. Yu, J. Zhao, W. Peng, A. Banazadeh, S. D. Williamson, M. Goli, Y. Huang and Y. Mechref, Electrophoresis, 2018, 39, 3104-3122.

20 M. Gaye, T. Ding, H. Shion, A. Hussein, Y. Hu, S. Zhou, Z. Hammoud, B. Lavine, Y. Mechref and J. Gebler, Analyst, 2017, 142, 1525-1535.

21 M. M. Gaye, S. J. Valentine, Y. Hu, N. Mirjankar, Z. T. Hammoud, Y. Mechref, B. K. Lavine and D. E. Clemmer, J. Proteome Res., 2012, 11, 6102-6110.

22 J. Hofmann and K. Pagel, Angew. Chem., Int. Ed. Engl., 2017, 56, 8342-8349.

23 C. Manz and K. Pagel, Curr. Opin. Chem. Biol., 2018, 42, 1624.

24 G. Lu, C. L. Crihfield, S. Gattu, L. M. Veltri and L. A. Holland, Chem. Rev., 2018, 118, 7867-7885.

25 Y. Mechref, Electrophoresis, 2011, 32, 3467-3481.

26 S. Suzuki, Anal. Sci., 2013, 29, 1117-1128.

27 S. Hua, C. C. Williams, L. M. Dimapasoc, G. S. Ro, S. Ozcan, S. Miyamoto, C. B. Lebrilla, H. J. An and G. S. Leiserowitz, J. Chromatogr. A, 2013, 1279, 58-67.

28 D. Kolarich, M. Windwarder, K. Alagesan and F. Altmann, Methods Mol. Biol., 2015, 1321, 427-435.

29 Y. Liu, C. Wang, R. Wang, Y. Wu, L. Zhang, B.-F. Liu, L. Cheng and X. Liu, J. Proteomics, 2018, 181, 160-169.

30 S. Zhou, Y. Huang, X. Dong, W. Peng, L. Veillon, D. A. S. Kitagawa, A. J. A. Aquino and Y. Mechref, Anal. Chem., 2017, 89, 6590-6597.

31 S. Zhou, L. Veillon, X. Dong, Y. Huang and Y. Mechref, Analyst, 2017, 142, 4446-4455.

32 R. Zhu, S. Zhou, W. Peng, Y. Huang, P. Mirzaei, K. Donohoo and Y. Mechref, J. Proteome Res., 2018, 17, 2668-2678.

33 F. Tousi, J. Bones, W. S. Hancock and M. Hincapie, Anal. Chem., 2013, 85, 8421-8428.

34 M. Wuhrer, A. R. de Boer and A. M. Deelder, Mass Spectrom. Rev., 2009, 28, 192-206.

35 G. C. Vreeker and M. Wuhrer, Anal. Bioanal. Chem., 2017, 409, 359-378.

36 R. R. Drake, T. W. Powers, E. E. Jones, E. Bruner, A. S. Mehta and P. M. Angel, Adv. Cancer Res., 2017, 134, 85-116.

37 D. J. Harvey, Mass Spectrom. Rev., 2015, 34, 268-422.

38 D. J. Harvey, Mass Spectrom. Rev., 2018, 37, 353-491.

39 W. R. Alley Jr and M. V. Novotny, J. Proteome Res., 2010, 9, 3062-3072.

40 N. de Haan, K. R. Reiding, M. Haberger, D. Reusch, D. Falck and M. Wuhrer, Anal. Chem., 2015, 87, 8284-8291.

41 K. Jiang, H. Zhu, L. Li, Y. Guo, E. Gashash, C. Ma, X. Sun, J. Li, L. Zhang and P. G. Wang, Anal. Chim. Acta, 2017, 981, 53-61.

42 H. Li, W. Gao, X. Feng, B.-F. Liu and X. Liu, Anal. Chim. Acta, 2016, 924, 77-85. 
43 K. R. Reiding, D. Blank, D. M. Kuijper, A. M. Deelder and M. Wuhrer, Anal. Chem., 2014, 86, 5784-5793.

44 D. Asakawa, N. Smargiasso and E. De Pauw, Anal. Chem., 2012, 84, 7463-7468.

45 D. Asakawa, N. Smargiasso and E. De Pauw, J. Mass Spectrom., 2014, 49, 1059-1062.

46 D. Debois, N. Smargiasso, K. Demeure, D. Asakawa, T. A. Zimmerman, L. Quinton and E. De Pauw, Top. Curr. Chem., 2013, 331, 117-141.

47 Q. Liang, T. Macher, Y. Xu, Y. Bao and C. J. Cassady, Anal. Chem., 2014, 86, 8496-8503.

48 H. Yang, Z. J. Li, D. Wan, W. Lian and S. Liu, J. Mass Spectrom., 2013, 48, 539-543.

49 H. Yang, Y. Yu, F. Song and S. Liu, J. Am. Soc. Mass Spectrom., 2011, 22, 845-855.

50 A. Banazadeh, W. Peng, L. Veillon and Y. Mechref, J. Am. Soc. Mass Spectrom., 2018, 29, 1892-1900.

51 M. Guan, Z. Zhang, S. Li, J. Liu, L. Liu, H. Yang, Y. Zhang, T. Wang and Z. Zhao, Talanta, 2018, 179, 624-631.

52 N. Hasan and H. F. Wu, Anal. Bioanal. Chem., 2011, 400, 3451-3462.

53 S. Ju and W. S. Yeo, Nanotechnology, 2012, 23, 135701135707.

54 C. Jun, H. Tianxi and F. Xuemei, Talanta, 2012, 100, 419-424.

55 S. K. Kailasa, S. D'Souza and H. F. Wu, Bioanalysis, 2015, 7, 2265-2276.

56 S. K. Kailasa and H. F. Wu, Analyst, 2012, 137, 1629-1638.

57 Q. Liang, J. Sherwood, T. Macher, J. M. Wilson, Y. Bao and C. J. Cassady, J. Am. Soc. Mass Spectrom., 2017, 28, 409-418.

58 X. S. Li, J. H. Wu, L. D. Xu, Q. Zhao, Y. B. Luo, B. F. Yuan and Y. Q. Feng, Chem. Commun., 2011, 47, 9816-9818.

59 Y. Chen, D. Gao, H. Bai, H. Liu, S. Lin and Y. Jiang, J. Am. Soc. Mass Spectrom., 2016, 27, 1227-1235.

60 W. Lu, Y. Li, R. Li, S. Shuang, C. Dong and Z. Cai, ACS Appl. Mater. Interfaces, 2016, 8, 12976-12984.

61 A. Banazadeh, S. Williamson, M. Zabet, A. Hussien and Y. Mechref, Anal. Bioanal. Chem., 2018, 410, 7395-7404.

62 Y. Liu, J. Liu, C. Deng and X. Zhang, Rapid Commun. Mass Spectrom., 2011, 25, 3223-3234.

63 Q. Liu, M. Cheng, J. Wang and G. Jiang, Chem. Eur. J, 2015, 21, 5594-5599.

64 S. Zhou, X. Dong, L. Veillon, Y. Huang and Y. Mechref, Anal. Bioanal. Chem., 2017, 409, 453-466.

65 A. Ceroni, K. Maass, H. Geyer, R. Geyer, A. Dell and S. M. Haslam, J. Proteome Res., 2008, 7, 1650-1659.

66 B. Domon and C. E. Costello, Glycoconjugate J., 1988, 5, 397409.

67 S. Hua, H. J. An, S. Ozcan, G. S. Ro, S. Soares, R. DeVereWhite and C. B. Lebrilla, Analyst, 2011, 136, 3663-3671.

68 M. Pabst and F. Altmann, Anal. Chem., 2008, 80, 7534-7542.

69 M. Pabst, J. S. Bondili, J. Stadlmann, L. Mach and F. Altmann, Anal. Chem., 2007, 79, 5051-5057.

70 K. N. Kirschner, A. B. Yongye, S. M. Tschampel, J. GonzálezOuteiriño, C. R. Daniels, B. L. Foley and R. J. Woods, J. Comput. Chem., 2008, 29, 622-655.
71 A. D. Becke, J. Chem. Phys., 1993, 98, 5648-5652.

72 A. Schäfer, H. Horn and R. Ahlrichs, J. Chem. Phys., 1992, 97, 2571-2577.

73 C. Hättig and F. Weigend, J. Chem. Phys., 2000, 113, 51545161.

74 S. Grimme, J. Antony, S. Ehrlich and H. Krieg, J. Chem. Phys., 2010, 132, 154104-154122.

75 R. Ahlrichs, M. Bär, M. Häser, H. Horn and C. Kölmel, Chem. Phys. Lett., 1989, 162, 165-169.

76 S. Albrecht, S. Vainauskas, H. Stöckmann, C. McManus, C. H. Taron and P. M. Rudd, Anal. Chem., 2016, 88, 47954802.

77 A. D. Garcia, J. L. Chavez and Y. Mechref, J Chromatogr B, 2014, 947, 1-7.

78 C. Hamark, R. P.-A. Berntsson, G. Masuyer, L. M. Henriksson, R. Gustafsson, P. 1. Stenmark and G. r. Widmalm, J. Am. Chem. Soc., 2016, 139, 218-230.

79 Y. Robert K, Y.-T. Tsai, T. Ariga and M. Yanagisawa, J. Oleo Sci., 2011, 60, 537-544.

$80 \mathrm{Y}$. Hu, T. Shihab, S. Zhou, K. Wooding and Y. Mechref, Electrophoresis, 2016, 37, 1498-1505.

81 A. Mayampurath, E. Song, A. Mathur, C. Y. Yu, Z. Hammoud, Y. Mechref and H. Tang, J. Proteome Res., 2014, 13, 48214832 .

82 K. R. Reiding, D. Blank, D. M. Kuijper, A. M. Deelder and M. Wuhrer, Anal. Chem., 2014, 86, 5784-5793.

83 C. M. Snyder, X. Zhou, J. A. Karty, B. R. Fonslow, M. V. Novotny and S. C. Jacobson, J. Chromatogr. A, 2017, 1523, 127-139.

84 S. Chen, H. Zheng, J. Wang, J. Hou, Q. He, H. Liu, C. Xiong, X. Kong and Z. Nie, Anal. Chem., 2013, 85, 6646-6652.

85 S. Miyagawa, A. Maeda, T. Kawamura, T. Ueno, N. Usui, S. Kondo, S. Matsumoto, T. Okitsu, M. Goto and H. Nagashima, Glycobiology, 2014, 24, 125-138.

86 S. Chen, C. Xiong, H. Liu, Q. Wan, J. Hou, Q. He, A. BaduTawiah and Z. Nie, Nat. Nanotechnol., 2015, 10, 176-182.

87 C. Jin, J. T. Padra, K. Sundell, H. Sundh, N. G. Karlsson and S. K. Linden, J. Proteome Res., 2015, 14, 3239-3251.

88 W. B. Struwe, R. Gough, M. E. Gallagher, D. T. Kenny, S. D. Carrington, N. G. Karlsson and P. M. Rudd, Mol. Cell. Proteomics, 2015, 14, 1464-1477.

89 V. Venkatakrishnan, M. P. Quintana-Hayashi, M. Mahu, F. Haesebrouck, F. Pasmans and S. K. Linden, J. Proteome Res., 2017, 16, 1728-1742.

90 G. Dekkers, A. E. H. Bentlage, R. Plomp, R. Visser, C. A. M. Koeleman, A. Beentjes, J. Y. Mok, W. J. E. van Esch, M. Wuhrer, T. Rispens and G. Vidarsson, Mol. Immunol., 2018, 94, 54-60.

91 A. Ogura, S. Urano, T. Tahara, S. Nozaki, R. Sibgatullina, K. Vong, T. Suzuki, N. Dohmae, A. Kurbangalieva, Y. Watanabe and K. Tanaka, Chem. Commun., 2018, 54, 8693-8696.

92 L. Zhan, X. Xie, Y. Li, H. Liu, C. Xiong and Z. Nie, Anal. Chem., 2018, 90, 1525-1530. 